\title{
EFEITO DE DIFERENTES PERÍODOS DE OCUPAÇÃO DA PASTAGEM DE CAPIM-ELEFANTE SOBRE A PRODUÇÃO DE LEITE ${ }^{1}$
}

\author{
ANTÔNIO CARLOS CÓSER ${ }^{2}$, CARLOS EUGÊNIO MARTINS ${ }^{2}$, DILERMANDO MIRANDA DA FONSECA ${ }^{3}$, \\ LUIIS TARCÍSIO SALGADO ${ }^{4}$, MAURÍLIO JOSÉ ALVIM ${ }^{5}$ e FLÁVIO VALERIANO TEIXEIRA ${ }^{6}$
}

\begin{abstract}
RESUMO - O trabalho objetivou determinar o melhor período de ocupação de pastagem de capimelefante (Pennisetum purpureum Schum. cv. Napier), na produção de leite. Foram testados três períodos de ocupação (1, 3 e 5 dias de pastejo), com 30 dias de descanso. O delineamento experimental usado foi de blocos casualizados, com duas repetições, durante três anos. Foi usada uma taxa de lotação de $4 \mathrm{UA} / \mathrm{ha}$. Durante o período experimental os animais recebiam suplementação concentrada, à base de $2,0 \mathrm{~kg} / \mathrm{vaca} / \mathrm{dia}$. Foram realizadas estimativas da disponibilidade e qualidade da forragem, da altura das plantas e da cobertura do solo a cada 14 dias, e registradas as produções de leite, diariamente. De acordo com os resultados, a disponibilidade e a qualidade da forragem e a produção de leite não foram influenciados pelos diferentes períodos de ocupação. No período das águas, foram observadas produções de leite de 10,9,10,8 e 10,8 kg/vaca/dia e 7.848, 7.800 e $7.776 \mathrm{~kg} / \mathrm{ha}$, nos tratamentos de 1,3 e 5 dias de ocupação, respectivamente $(\mathrm{P}>0,05)$. As maiores flutuações na produção diária de leite por vaca ocorreram no tratamento com cinco dias de pastejo, explicadas pela redução de forragem em quantidade e qualidade, ao longo do período de ocupação em cada piquete.
\end{abstract}

Termos para indexação: dias de descanso, dias de ocupação, pastejo rotativo, produção animal.

\section{EFFECT OF DIFFERENT GRAZING PERIODS IN ELEPHANT GRASS PASTURE UPON MILK PRODUCTION}

\begin{abstract}
Elephant grass (Pennisetum purpureum Schum. cv. Napier) pastures were grazed by lactating dairy cows with the aim of assessing the best grazing period to maximize milk production. Three grazing periods (1, 3 and 5 days, with 30 days resting) were tested using a randomized block design, with two replications, during three years. Each paddock was grazed by 4 milking cows. During the experimental period, the cows received individually $2,0 \mathrm{~kg} /$ day of a concentrate mixture. Estimates of forage availability and quality, plant height, ground cover and milk production, were recorded. Results showed that available forage and quality and milk production were not influenced by the three different grazing periods. Average milk production/cow/day in the rainy season were 10.9, 10.8 and $10.8 \mathrm{~kg}$ and the average milk yields per hectare were 7,848,7,800 and 7,776 kg/ha for 1, 3 or 5 grazing days, respectively $(\mathrm{P}>0.05)$. The largest flotations in dairy milk yield per cow occurred in the five grazing days treatment, explained for both forage availability and quality decreases along the grazing period on each paddock.
\end{abstract}

Index terms: resting period, grazing days, rotational grazing, animal production.

${ }^{1}$ Aceito para publicação em 25 de agosto de 1998.

${ }^{2}$ Eng. Agr., Dr., Embrapa-Centro Nacional de Pesquisa de Gado de Leite (CNPGL), Rua Eugênio do Nascimento, 610, CEP 36038-330 Juiz de Fora, MG. Bolsista do CNPq. E-mail: acoser@cnpgl.embrapa.br

${ }^{3}$ Eng. Agr., Dr., Prof. Adjunto, Dep. de Zootecnia, UFV, CEP 36571-000 Viçosa, MG. Bolsista do CNPq.

${ }^{4}$ Eng. Agr., M.Sc., Embrapa/EPAMIG, CEP 36571-000 Viçosa, MG.

${ }^{5}$ Biólogo, M.Sc., Embrapa-CNPGL. Bolsista do CNPq.

${ }^{6}$ Eng. Agr., Aluno do Curso de Mestrado, UFRRJ, Seropédica, RJ.

\section{INTRODUÇÃO}

O uso eficiente de forrageiras e pastagens, como base da alimentação animal, representa uma das formas para garantir o aumento em produtividade e a redução nos custos da exploração leiteira. Nesse sentido, o capim-elefante (Pennisetum purpureum Schum. cv. Napier) tem se destacado entre as forrageiras mais utilizadas nos sistemas de produção de leite, em decorrência do seu elevado potencial 
produtivo e da sua qualidade. No entanto, para que haja aumento da produção de leite por animal e por área, é necessário o conhecimento do equilíbrio entre quantidade e qualidade da forragem que permita esse desempenho. Deve-se considerar que a prática da fertilização da pastagem influencia positivamente na melhoria da quantidade e da qualidade da forragem produzida, sendo a resposta dependente da espécie vegetal, entre outras coisas. Sabe-se que o capim-elefante é capaz de mostrar elevado rendimento de forragem, quando convenientemente manejado e adubado (Corsi \& Nussio, 1992). Por essa razão, tem sido crescente o interesse pelos pecuaristas em utilizá-lo no estabelecimento de pastagens para vacas em lactação, visando à intensificação da produção de leite.

Embora o seu emprego sob pastejo apresente excelentes perspectivas, alguns problemas decorrentes desta forma de utilização têm sido apontados. Gomide (1990) ressalta o acentuado caráter sazonal da sua produção, e Veiga (1990) registra a dificuldade de manejo pelo seu hábito de crescimento ereto e ascendente, chegando, muita vezes, a atingir alturas fora do alcance dos animais.

Espécies que exibem hábito de crescimento ereto, como o capim-elefante, devem ser manejadas sob pastejo rotativo, para maior eficiência (Blaser et al., 1973; Morley, 1981). Assim, deve-se interromper o pastejo em determinado momento, para que haja recomposição da área foliar, da qual depende a formação de reservas orgânicas. É sabido que a área foliar remanescente, após corte ou pastejo, influi sensivelmente na velocidade e intensidade da rebrota, razão pela qual se deve evitar o superpastejo, promovendo um período de descanso necessário para boa recuperação das plantas.

Uma boa pastagem de capim-elefante suporta facilmente de 3 a $4 \mathrm{UA} /$ ha, durante a estação das águas. Já, no período seco, o crescimento e o valor nutritivo são reduzidos e a capacidade de suporte cai consideravelmente, sugerindo a adoção de medidas para a suplementação do rebanho nessa época. Lucci et al. (1972), testando uma pastagem de capim-elefante, sob uma taxa de lotação de 3,6 vacas/ha, demonstraram que essa pastagem tem condições de fornecer nutrientes necessários para manutenção e produção de leite de $11,6 \mathrm{~kg} / \mathrm{vaca} / \mathrm{dia}$ de leite. Produções de leite de aproximadamente $13 \mathrm{~kg} / \mathrm{vaca} / \mathrm{dia}$, em pastagens de capim-elefante, são relatadas no trabalho de Deresz (1994), sem o uso de concentrados. Na época seca, no entanto, o crescimento e o valor nutritivo são reduzidos, necessitando-se a adoção de medidas para a suplementação alimentar do rebanho.

Para Corsi (1986), pastagens de alta produção, como as de capim-elefante, quando suplementadas no período seco, podem apresentar um potencial de produção de $10.500 \mathrm{~kg}$ de leite/ha/ano. O mesmo autor informa que, dependendo da eficiência reprodutiva, do período de lactação e da composição do rebanho, essa produção poderá chegar a $26.000 \mathrm{~kg} / \mathrm{ha} /$ ano. Resultados superiores a esses são relatados por Cruz Filho et al. (1996), em pastagem de capim-elefante irrigado, na Região Norte de Minas Gerais, onde foram obtidas produções de leite acima de $30.000 \mathrm{~kg} / \mathrm{ha} / \mathrm{ano}$.

No entanto, informações sobre o seu manejo para obtenção de produções elevadas de leite são ainda necessárias. Este trabalho teve como objetivo determinar o melhor período de ocupação em pastagem de capim-elefante sobre a produção de leite.

\section{MATERIAL E MÉTODOS}

O experimento foi conduzido na Fazenda Experimental Santa Mônica, da Embrapa-Centro Nacional de Pesquisa de Gado de Leite (CNPGL), município de Valença, RJ, durante três anos (1991-1994).

Foram testados três períodos de ocupação da pastagem (1, 3 e 5 dias), com trinta dias de descanso, sendo os tratamentos dispostos em blocos ao acaso, com duas repetições por tratamento.

A área de capim-elefante cv. Napier, por ocasião do estabelecimento, foi arada, aplicou-se nela o calcário dolomítico à base de $2 \mathrm{t} / \mathrm{ha}$, e, em seguida, foi gradeada. Os sulcos, com $20 \mathrm{~cm}$ de profundidade e com espaços, entre si, de $70 \mathrm{~cm}$, foram adubados com $100 \mathrm{~kg} / \mathrm{ha}$ de $\mathrm{P}_{2} \mathrm{O}_{5}$, tendo como fonte o superfosfato simples.

O plantio do capim-elefante foi realizado no início do período chuvoso, usando-se colmos distribuídos no sistema "pé-com-ponta", com cortes a intervalo de $70 \mathrm{~cm}$, no próprio sulco.

A partir do primeiro ano, foram aplicados em cobertura, anualmente, $200 \mathrm{~kg} /$ ha de $\mathrm{N}$ (sulfato de amônio) e $\mathrm{K}_{2} \mathrm{O}$ (cloreto de potássio), respectivamente, e $60 \mathrm{~kg} / \mathrm{ha}$ de $\mathrm{P}_{2} \mathrm{O}_{5}$ (superfosfato simples). $\mathrm{O} \mathrm{N}$ e o $\mathrm{K}$ foram parcelados em 
três aplicações, no início, meio e final do período chuvoso. O superfosfato simples foi aplicado em sua totalidade junto à primeira aplicação de $\mathrm{N}$ e $\mathrm{K}_{2} \mathrm{O}$.

Para a execução deste trabalho foram selecionadas vacas mestiças Holandês x Zebu, provenientes do rebanho leiteiro da Embrapa-CNPGL. A distribuição dos animais nos tratamentos foi baseada nos critérios produção de leite e data de parição. Em cada período do ano, em cada ano, foram usados diferentes grupos de animais.

Durante o período experimental, as vacas foram ordenhadas duas vezes ao dia, às 6 e 14 horas, respectivamente.

Foi utilizada uma carga animal de $4 \mathrm{UA} / \mathrm{ha}$, e a área de cada parcela foi estabelecida considerando-se 1 ha, dividido pelo número de piquetes necessários para os respectivos períodos de ocupação e descanso (Tabela 1). Desse modo, a área experimental perfez um total de 6 ha, utilizando 24 animais.

Tanto no período chuvoso como no seco, as vacas recebiam $2 \mathrm{~kg} /$ animal $/$ dia de um concentrado com $17 \%$ de proteína bruta, sendo metade pela manhã e metade à tarde.

No período seco do ano, além do concentrado, as vacas receberam a suplementação com cana picada mais $1 \%$ de uréia à vontade, entre as ordenhas, retornando à pastagem após a segunda ordenha.

Antes e depois do pastejo dos piquetes, foram realizadas cinco amostragens de disponibilidade de forragem em cada tratamento/repetição, por meio do corte do capimelefante, a $40 \mathrm{~cm}$ do nível do solo, a cada 14 dias durante o

TABELA 1. Períodos de ocupação, número e área de piquetes em cada tratamento.

\begin{tabular}{ccc}
\hline $\begin{array}{c}\text { Período ocupação } \\
\text { (dia) }\end{array}$ & $\begin{array}{c}\text { Número de } \\
\text { piquetes }\end{array}$ & $\begin{array}{c}\text { Área do piquete } \\
\left(\mathrm{m}^{2}\right)\end{array}$ \\
\hline 1 & 31 & 323 \\
3 & 11 & 909 \\
5 & 7 & 1.429 \\
\hline
\end{tabular}

período chuvoso, e a cada 28 dias na época seca. Todas as amostras foram separadas em caules e folhas. Antes do corte, porém, em cada local de amostragem foi medida a altura das plantas (m), usando-se régua graduada com intervalos de $5 \mathrm{~cm}$ e estimada visualmente a cobertura do solo pelas plantas (\%). Somente nas amostras de matéria seca do componente folhas verdes eram estimados os teores de proteína bruta (PB) e digestibilidade in vitro da matéria seca (DIVMS).

Amostras de solo foram retiradas, anualmente, de 0-20 $\mathrm{cm}$ de profundidade, para análise de rotina, de modo a monitorar a fertilidade do solo e permitir recomendação de adubação anual de manutenção da pastagem.

A produção de leite foi registrada diariamente, e a variação do peso vivo, a cada 28 dias, quando também era estimado o escore corporal das vacas.

\section{RESULTADOS E DISCUSSÃO}

Não se verificou influência dos diferentes períodos de pastejo sobre a produção de matéria seca e a cobertura do solo pelas plantas, avaliados a cada 14 dias (Tabelas 2 e 3 ).

As estimativas de cobertura do solo mostraram uma tendência de aumento com o passar do tempo, independentemente do período de ocupação utilizado. A adubação anual e possivelmente a reciclagem de nutrientes no sistema podem explicar o acréscimo de cobertura vegetal ocorrido no período, e não se observou a presença de invasoras na pastagem.

Não foi observada diferença entre tratamentos com relação ao teor de proteína bruta e à digestibilidade in vitro da matéria seca das folhas (Tabela 4). Apenas houve uma pequena diferença entre o peso vivo e o escore corporal das vacas (Tabela 5), determinados mensalmente, o que não provocou alteração na produção de leite (Tabelas 6 e 7).

TABELA 2. Disponibilidade de forragem (matéria seca de caule e de folhas - $\mathrm{kg} / \mathrm{ha}$ ) em pastagem de capim-elefante submetida a diferentes períodos de ocupação, durante a estação chuvosa (média de três anos) ${ }^{1}$.

\begin{tabular}{cccc}
\hline \multirow{2}{*}{$\begin{array}{c}\text { Período de } \\
\text { ocupação (dia) }\end{array}$} & \multicolumn{3}{c}{$\begin{array}{c}\text { Matéria seca } \\
(\mathrm{kg} / \mathrm{ha})\end{array}$} \\
\cline { 2 - 4 } & Caules & Folhas & Total \\
\hline 1 & 3.251 & 2.944 & 6.195 \\
3 & 3.044 & 2.641 & 5.685 \\
5 & 2.979 & 2.912 & 5.891 \\
\hline
\end{tabular}


TABELA 3. Cobertura estimada do solo (\%) em pastagem de capim-elefante submetida a diferentes períodos de ocupação, durante as estações chuvosas.

\begin{tabular}{cccc}
\hline \multirow{2}{*}{$\begin{array}{c}\text { Período de } \\
\text { ocupação (dia) }\end{array}$} & \multicolumn{3}{c}{ Cobertura do solo (\%) } \\
\cline { 2 - 4 } & $1991 / 1992$ & $1992 / 1993$ & $1993 / 1994$ \\
\hline 1 & 46 & 52 & 52 \\
3 & 43 & 50 & 51 \\
5 & 44 & 52 & 51 \\
\hline
\end{tabular}

TABELA 4. Teores médios de proteína bruta (PB) e da digestibilidade in vitro da matéria seca das folhas (DIVMS) em pastagem de capim-elefante submetida a diferentes períodos de ocupação, durante as estações chuvosas de 1991/1992 e 1992/19931.

\begin{tabular}{ccc}
\hline $\begin{array}{c}\text { Período de } \\
\text { ocupação } \\
\text { (dia) }\end{array}$ & PB & $\begin{array}{c}\text { DIVMS } \\
(\%)\end{array}$ \\
\hline 1 & $(\%)$ & 65,1 \\
3 & 15,6 & 66,3 \\
5 & 14,9 & 64,9 \\
\hline
\end{tabular}

${ }^{1}$ Amostragem realizada antes do pastejo.

TABELA 5. Médias do peso vivo e do escore corporal de vacas em pastagem de capim-elefante submetida a diferentes períodos de ocupação durante as estações chuvosas (média de três anos).

\begin{tabular}{ccc}
\hline $\begin{array}{c}\text { Período de } \\
\text { ocupação } \\
\text { (dia) }\end{array}$ & $\begin{array}{c}\text { Peso vivo } \\
(\mathrm{kg})\end{array}$ & Escore corporal \\
\hline 1 & 469 & 3,3 \\
3 & 457 & 3,2 \\
5 & 471 & 3,6 \\
\hline
\end{tabular}

A produção de leite não foi afetada $(\mathrm{P}>0,05)$ pelos diferentes períodos de utilização da pastagem, nos três anos de avaliação (Tabela 6). As maiores produções de leite verificadas no segundo e terceiro ano estão relacionadas à utilização de vacas com maior potencial leiteiro. Deresz (1994) encontrou produções de leite bastante superiores às registradas neste trabalho (em torno de $13 \mathrm{~kg} / \mathrm{vaca} / \mathrm{dia}$ ), usando vacas mestiças de maior capacidade genética, durante o período chuvoso, o que demonstra o grande potencial dessa forrageira para produção de leite em sistemas intensivos.

O capim-elefante apresenta produção de forragem tipicamente sazonal, o que indica ser necessária a suplementação do rebanho na época crítica do ano. As produções médias de leite na época seca são apresentadas na Tabela 7. Pode-se observar que não houve diferença na produção de leite nos três períodos de ocupação estudados, porque a ingestão de nutrientes dependeu quase que exclusivamente do volumoso (cana $+1 \%$ de uréia), acrescido de concentrado à base de $2 \mathrm{~kg} / \mathrm{vaca} /$ dia.

O somatório das produções de leite por área, baseado no sistema de pastejo em capim-elefante na época chuvosa (Tabela 6) e na alimentação suplementar na época seca (Tabela 7) proporcionou produções anuais de leite de 14.760, 14.736 e $14.568 \mathrm{~kg}$ /ha para um, três e cinco dias de ocupação, respectivamente. Essa produção de leite é aproximadamente 15 vezes mais elevada que a média brasileira, que é inferior a $1.000 \mathrm{~kg} / \mathrm{ha}$.

Foram verificadas variações diárias na produção de leite em pastagens de capim-elefante manejadas com períodos de ocupação de um, três e cinco dias de pastejo, conforme pode ser visto na Fig. 1. As produções de leite foram bastante uniformes com um dia de pastejo, pelo fato de a utilização da forragem disponível em um dia proporcionar uma qualidade média uniforme, minimizando o pastejo seletivo. Por outro lado, quando os animais utilizam a 
TABELA 6. Produções médias de leite por animal (kg/vaca/dia) e por área (kg/ha), em pastagem de capimelefante submetida a diferentes períodos de ocupação, durante as estações chuvosas.

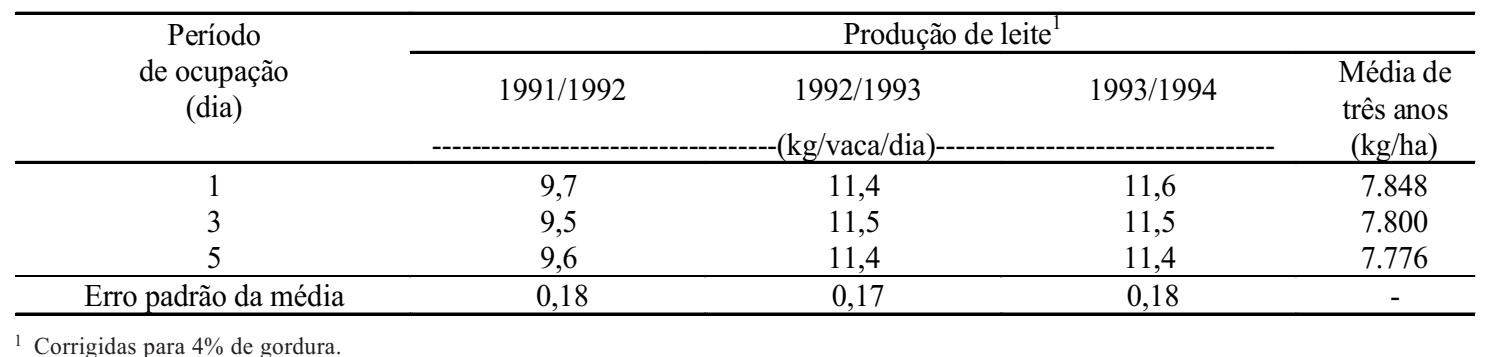

TABELA 7. Produções médias de leite por animal $(\mathrm{kg} / \mathrm{vaca} / \mathrm{dia})$ e por área $(\mathrm{kg} / \mathrm{ha})$ de vacas suplementadas com cana-de-açúcar mais $1 \%$ de uréia, em pastagem de capim-elefante submetida a diferentes períodos de ocupação, durante a época seca.

\begin{tabular}{|c|c|c|c|c|}
\hline \multirow{2}{*}{$\begin{array}{c}\text { Período } \\
\text { de ocupação } \\
\text { (dia) }\end{array}$} & \multicolumn{4}{|c|}{ Produção de leite $^{\top}$} \\
\hline & 1992 & $\begin{array}{l}1993 \\
/ \mathrm{vaca} / \mathrm{d}\end{array}$ & 1994 & $\begin{array}{c}\text { Média de } \\
\text { três anos } \\
(\mathrm{kg} / \mathrm{ha})\end{array}$ \\
\hline 1 & 9,5 & 9,8 & 9,5 & 6.912 \\
\hline 3 & 9,4 & 10,1 & 9,4 & 6.936 \\
\hline 5 & 9,4 & 9,8 & 9,1 & 6.792 \\
\hline Erro padrão da média & 0,19 & 0,20 & 0,22 & - \\
\hline
\end{tabular}

${ }^{1}$ Corrigidas para $4 \%$ de gordura.

forragem de um piquete de capim-elefante em pastejo durante vários dias, o valor nutritivo da forragem é mais alto no primeiro dia e mais baixo no último (Tabela 8). Nessa situação, a produção de leite por vaca aumenta por alguns dias, alcança um platô e declina quando um novo piquete é utilizado (Fig. 1). Essas oscilações na produção de leite estão diretamente associadas com o pastejo seletivo, que promove um consumo mais alto de matéria seca digestível durante o primeiro dia, e mais baixo no último dia de pastejo num mesmo piquete, conforme registra Blaser et al. (1986). A redução na produção de leite, que ocorre próximo ao final do período de pastejo em cada piquete, reflete o efeito residual do consumo de forragem de baixa digestibilidade, persistindo esse efeito quando as vacas são colocadas num novo piquete. Após um ou dois dias num novo piquete, esse efeito torna-se nulo pelo consumo de forragem mais digestível e, conseqüentemente, a produção de leite volta a aumentar. Milera

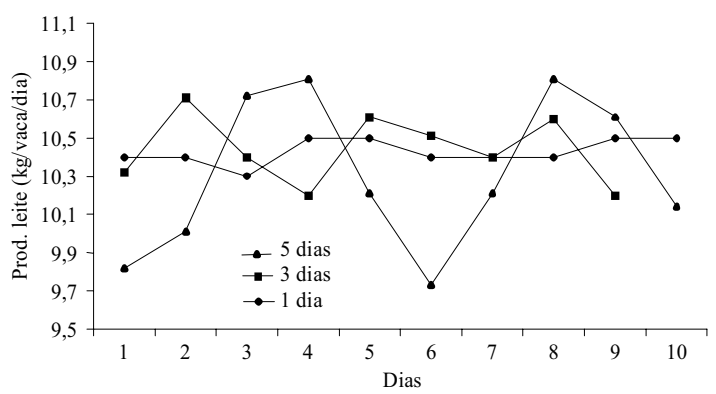

FIG. 1. Variação diária na produção de leite de vacas em pastagem de capim-elefante manejada com períodos de ocupação de 1, 3 e 5 dias, durante dez dias, no período chuvoso de 1991/1992.

\& Menchaca (1987) observaram que vacas em pastagem de Cynodon dactylon cv. Coastcross-1 não devem permanecer mais que quatro dias pastejando essa forrageira, pois além desse tempo caem a quantidade e a qualidade da forragem ingerida pelos animais. Tais resultados são semelhantes aos relatados por Milera et al. (1986) e aos obtidos neste experimento. 
TABELA 8. Teores médios de proteína bruta e digestibilidade in vitro da matéria seca de folhas verdes em pastagens de capim-elefante submetidas a diferentes períodos de ocupação durante uma seqüência de dias de pastejo - época chuvosa.

\begin{tabular}{|c|c|c|c|c|c|c|}
\hline \multirow{2}{*}{$\begin{array}{l}\text { Período de ocupação } \\
\text { (dia) }\end{array}$} & \multicolumn{6}{|c|}{ Seqüência de dias de pastejo } \\
\hline & $1^{0}$ dia & $2^{\underline{0}}$ dia & $3^{\mathrm{o}}$ dia & $4^{\mathrm{O}}$ dia & $5^{0}$ dia & $6^{0}$ dia \\
\hline & \multicolumn{6}{|c|}{ Proteína bruta $(\%)$} \\
\hline 1 & 18,6 & 11,7 & & & & \\
\hline 3 & 17,3 & 14,8 & 13,1 & 11,3 & & \\
\hline \multirow[t]{2}{*}{5} & 17,2 & 15,6 & 14,1 & 12,8 & 11,9 & 10,9 \\
\hline & \multicolumn{6}{|c|}{ Digestibilidade in vitro da matéria seca (\%) } \\
\hline 1 & 71,3 & 60,9 & & & & \\
\hline 3 & 72,4 & 68,9 & 63,5 & 59,5 & & \\
\hline 5 & 70,2 & 70,0 & 67,6 & 61,7 & 60,4 & 58,1 \\
\hline
\end{tabular}

\section{CONCLUSÕES}

O período de ocupação de pastagens de capimelefante usadas por vacas em lactação pode variar de um a cinco dias, sem prejuízo para as produções de leite por animal e por hectare.

\section{REFERÊNCIAS}

BLASER, R.E.; HAMMES JÚNIOR, R.C.; FONTENOT, J.P.; BRYANT, H.T.; POLAN, C.E.; WOLF, D.E.; McCLAUGHERTY, F.S.; KLINE, R.G.; MOORE, J.S. Forage-animal management systems. Virginia: Virginia Polytechnic Institute and State Univ., 1986. 90p.

BLASER, R.E.; WOLF, D.D.; BRYANT, H.T. Systems of grazing management. In: HEATH, M.E.; METCALF, D.S.; BARNES, R.E. (Eds.). Forages. Ames: Iowa State Univ. Press., 1973. p.581-595.

CORSI, M.; Pastagens de alta produtividade. In: CONGRESSO BRASILEIRO DE PASTAGENS, 8 ., 1986, Piracicaba. Anais... Piracicaba: FEALQ, 1986. p.499-512.

CORSI, M.; NUSSIO, L.G. Manejo do capim-elefante: correção e adubação do solo. In: SIMPÓSIO SOBRE MANEJO DE PASTAGENS, 1992, Piracicaba. Anais... Piracicaba: USP-ESALQ, 1992. p.87-115.

CRUZ FILHO, A.B.; CÓSER, A.C.; PEREIRA, A.V.; MARTINS, C.E.; TELES, F.M.; VELOSO, J.R.; BARBOSA NETO, E.; COSTA, R.V.; COSTA, C.W.C. Produção de leite a pasto usando capim-elefante: Dados parciais de transferência de tecnologia no Norte de Minas Gerais. In: REUNIÃO DA SOCIEDADE BRASILEIRA DE ZOOTECNIA, 33., 1996, Fortaleza. Anais... Fortaleza: SBZ, 1996. v.1, p.504-506.
DERESZ, F. Manejo de pastagem de capim-elefante para produção de leite e carne. In: SIMPÓSIO SOBRE CAPIM-ELEFANTE, 2., 1994, Coronel Pacheco. Anais... Coronel Pacheco: EmbrapaCNPGL, 1994. p.116-137.

GOMIDE, J.A. Formação e utilização de capineira de capim-elefante. In: SIMPÓSIO SOBRE CAPIMELEFANTE, 2., 1990, Coronel Pacheco. Anais... Coronel Pacheco: Embrapa-CNPGL, 1990. p.59-87.

LUCCI, C. S.; ROCHA, G.L. da; FREITAS, E.A.N. Produção de leite em regime exclusivo de capim fino e napier. Boletim da Indústria Animal, Nova Odessa, v.29, n.1, p.45-52, 1972.

MILERA, M.; MARTÍNEZ, J.; CÁCERES, O.; HERNÁNDEZ, J. Influencia del nivel de oferta en la producción de leche según los dias de estancia en la bermuda cruzada-1. Pastos y Forrajes, Matanzas, v.9, n.2, p.167-176, 1986.

MILERA, M.; MENCHACA, M. Comportamiento de vacas $\mathrm{F}_{1}(\mathrm{H}$ x C) en pastoreo de Cynodon dactylon cv. Coastcross- 1 com diferentes tiempos de estancia. Pastos y Forrajes, Matanzas, v.10, n.2, p.176-182, 1987.

MORLEY, F.H.W. Management of grazing systems. In: MORLEY, F.H.W. (Ed.). World animal science (B1) disciplinary approach: grazing animals. Amsterdam: Elsevier, 1981. p.379-399.

VEIGA, J.B. Utilização de capim-elefante sob pastejo. In: SIMPÓSIO DE CAPIM-ELEFANTE, 2., 1990, Coronel Pacheco. Anais... Coronel Pacheco: Embrapa-CNPGL, 1990. p.133-154. 